\title{
Left Femoral Artery Occlusion due to Neglected Closed Fracture Distal Femur: A Case Report
}

\author{
Pamudji Utomo',2), Totok Siswanto3) \\ ${ }^{1)}$ Department of Orthopaedics and Traumatology, Prof. Dr. R. Soeharso Orthopaedics Hospital/ \\ Faculty of Medicine, Universitas Sebelas Maret \\ 2)Karima Utama Surgical Hospital, Surakarta \\ 3)Department of Emergency, Karima Utama Surgical Hospital, Surakarta
}

\begin{abstract}
Background: Distal femur fractures must always be considered for vascular disorders given the high risk. The incidence rate of femoral fractures is $1 / 10000$ patients per year with the incidence rate of vascular injury around $0.10 \%-2.00 \%$. Salter-Harris $(\mathrm{SH})$ fracture classification is used in cases of fractures involving the growth plate (physeal plate) in children. Volkmann's ischemic contracture is caused by severe injury to the deep tissue and nerves. If tissue pressure is equal to or more than the perfusion pressure of the capillary, the microcirculation will be disrupted and ischemic occur. Normal myosit cells will be replaced by fibroblasts that tend to contract.

Subjects and Method: A 10 years old boy had a traffic accident while riding a motorcycle 6 days before the patient came to the hospital. The patient could not walk, feeling pain and swelling on the left knee, the patient didn't bring to the hospital immediately after the accident. On physical examination, there was angulation in the distal left femur, there was tenderness on palpation and unable to do dorsiflexion or moving the fingers of the left foot but still could feel touch stimulation on the pedis.

Results: In our patient case with the diagnosis of left femoral artery occlusion et causa closed fracture distal femur (Salter-Harris type II) managed by surgery to release the femoral artery with internal fixation to the distal femur using Kirschner wire (minimally invasive) and massage to the femoral artery give optimal results.

Conclusion: Surgery to release the femoral artery with internal fixation to the distal femur using Kirschner wire (minimally invasive) and massage to the femoral artery give an optimal result.
\end{abstract}

Keywords: Salter-Harris fracture, femoral artery, Kirschner wire, Volkmann's ischaemic contracture

\section{Correspondence:}

Pamudji Utomo. Department of Orthopaedics and Traumatology, Prof. Dr. R. Soeharso Orthopaedics Hospital. Email: utomodr@yahoo.com

\section{BACKGROUND}

The most common causes of injuries are traffic accidents and sports injuries. Femoral fractures are very common in the community for less than 25 years and over 65 years old. The incidence rate of femoral fractures is $1 / 10,000$ patients per year with the incidence rate of vascular injury about 0.10\%-2.00\% (Aydin et al., 2012; Sperofoulos, 2014; Zagorac et al., 2016).

Given the high incidence of vascular and neurological injury within knee dis- location in children and fractures of shifting growth plates, understanding of clinical, radiographic, reduction techniques and surgical management is very important. Complications such as vascular injury, neurological injury and compartment syndrome must be diagnosed as early as possible to avoid dangerous complications. A clinical examination must include motor and sensory examination of the foot, and palpation of the pulse (Mayer et al., 2015; Sperofoulos, 2014). 
Indonesian Journal of Medicine (2019), 4(1): 75-81

https://doi.org/10.26911/theijmed.2019.04.01.12

\section{CASE REPORT}

In this case report, the patient's data was obtained from Karima Utama Surgical Hospital, Surakarta. The patient, BFP, 10 years old boy had a traffic accident while riding a motorcycle 6 days before the patient came to the hospital. The patient could not walk, feeling pain and swelling on the left knee, the patient didn't bring to the hospital immediately after the accident.
On physical examination, there was angulation in the distal left femur, there was tenderness on palpation and unable to do dorsiflexion or moving the fingers of the left foot but still could feel touch stimulation on the pedis. From $\mathrm{SpO} 2$ examination on the digiti I to $\mathrm{V}$, the result is displayed in Table 1. Then a radiological examination is performed to see the femur bone.

Table 1. The Result of SpO2 Examination on Left Pedis

\begin{tabular}{cccccc}
\hline Time & Dig I & Dig II & Dig III & Dig IV & Dig V \\
\hline o Min & $0 \%$ & $0 \%$ & $0 \%$ & $0 \%$ & $0 \%$ \\
10 Min & $0 \%$ & $0 \%$ & $0 \%$ & $0 \%$ & $0 \%$ \\
30 Min & $0 \%$ & $0 \%$ & $0 \%$ & $0 \%$ & $0 \%$ \\
1 Hour & $0 \%$ & $0 \%$ & $0 \%$ & $0 \%$ & $0 \%$ \\
\hline
\end{tabular}

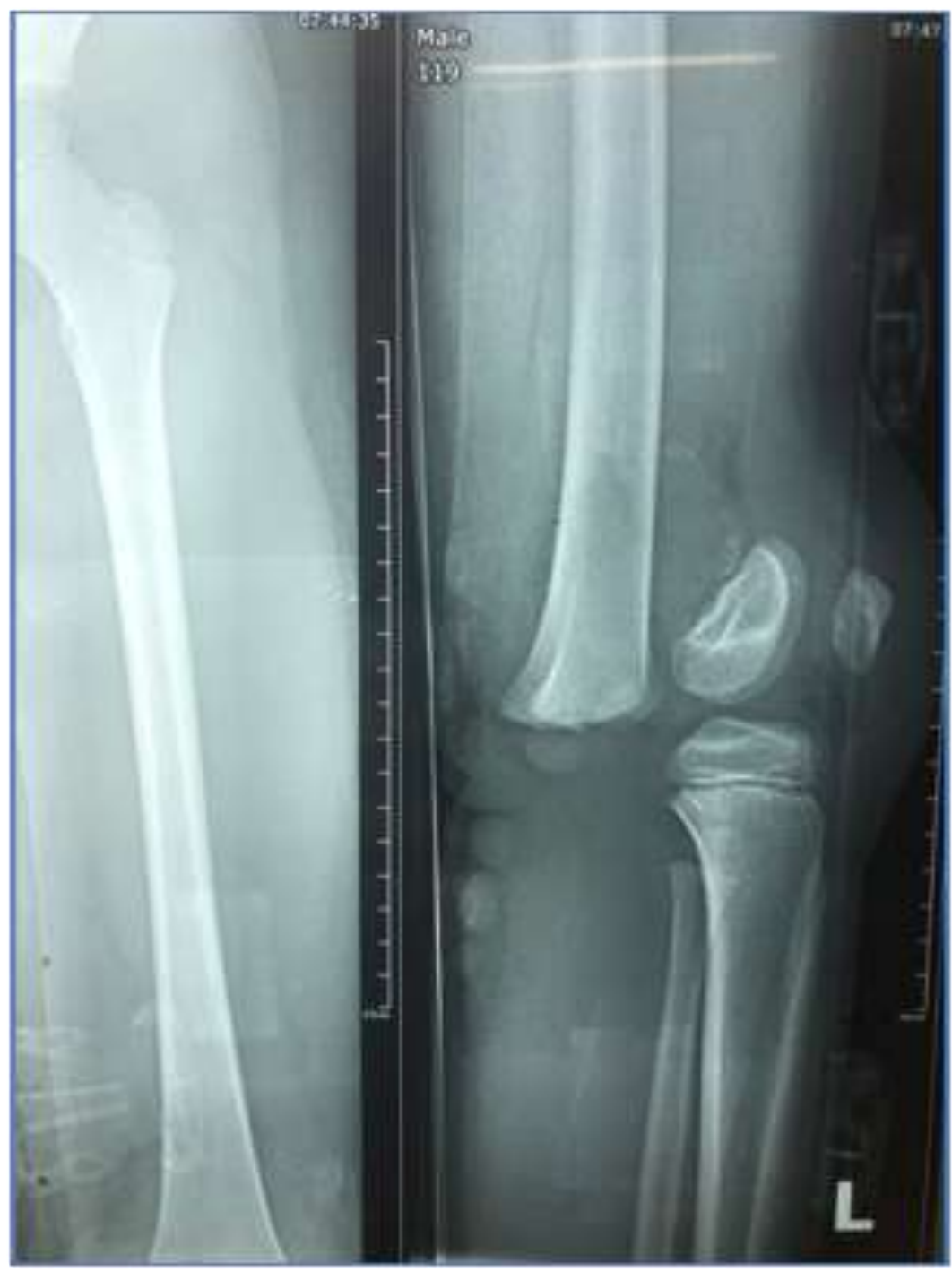

Figure 1. Left femur X-ray result 
After radiological examination, closed fracture of the distal left femur (salterharris type II) with posterior metaphysis translation was found. Because the examination with pulse oximetry resulted in $0 \%$, it was suspected there was occlusion in the left femoral artery. The patient diagnosed with closed fracture distal femur (salterharris type II) with occlusion in the left femoral artery so surgery was performed.

\section{DISCUSSION}

Acute arterial occlusion, also known as acute ischemic, is a vascular emergency. Acute ischemia is defined as loss of perfusion of the extremities up to 2 weeks from the event. Acute arterial occlusion can occur in the upper extremities or lower extremities (Smith and Bhimji, 2018).

In long bone fractures with vascular injury, it is necessary to perform a deeper examination. Although there is no consensus stated the order of surgery, restore the vascular function and reperfusion after improving hemostasis have to be the priority. Prevention of ischemic muscle tissue due to late treatment must be a top priority (Basbug et al., 2017).

In 1881 Volkmann stated that paralytic contracture can occur several hours after an injury is caused by arterial insufficient or ischaemic muscle. Volkmann's ischaemic contracture is caused by severe injury to the deep muscle tissue and nerves. Ischaemic can still be tolerated if no more than 4 hours, but after 6 hours the viability of the muscle still varies and irreversible damage occurs in a case with more than 8 hours loss of tissue perfusion (Farzad et al., 2010; Maheshwar et al, 2015; Zoran et al., 2016).

Rigid fascia makes only a small increase in volume. Above a certain number, the pressure will increase than the volume. Pressure on tissues varies from 0 to $8 \mathrm{mmHg}$ and capillary perfusion pres- sure is 30 to $40 \mathrm{mmHg}$. If tissue pressure is equal to or more than the perfusion pressure of the capillary, the microcirculation will be disrupted and ischaemic occur. Normal myocyte cells will be replaced by fibroblasts that tend to contract. Ischaemic on nerves causes severe pain and sensibility disorders to occur prior to motor function (Abela and Vanniasinkham, 2003; Kingori and Gakuu, 2010; Reurings and Verhofstad, 2007; Wind et al., 2012).

The femoral artery is the main artery in the thigh which is a continuation of the external iliac artery. The femoral artery is the main artery of the lower extremity that supplies blood to the anterior, medial and lateral compartment muscles of the thigh. The femoral artery will become popliteal artery which divided become anterior and posterior tibial arteries (Figure 2). Risk of popliteal artery occlusion higher in distal femoral physis fracture with the bone shift towards the anterior (Ajankar et al., 2014; Aydin et al., 2012; Zlotorowicz and Czubak, 2014).

Salter-Harris fracture in distal femur must be considered a knee dislocation so it included in emergency orthopedics. In the distal fracture femur, vascular disorders must always be considered given the high risk (Kuleta-Bosak et al., 2010; McKenna et al., 2013; Murdock, 2015).

Salter-Harris (SH) fracture classification is used in cases of fractures involving the growth plate (physeal plate) in children. Classification based on fracture patterns of growth plates and its surrounding bones. Salter-Harris type I fractures has the lowest incidence of disrupting bone growth (34\%) where Salter-Harris type IV has the highest incidence (64\%) (Aydin et al., 2012; Cepela et al., 2016; Murdock, 2015). Figure 3 shows Salter-Harris fracture classification. 
Indonesian Journal of Medicine (2019), 4(1): 75-81

https://doi.org/10.26911/theijmed.2019.04.01.12
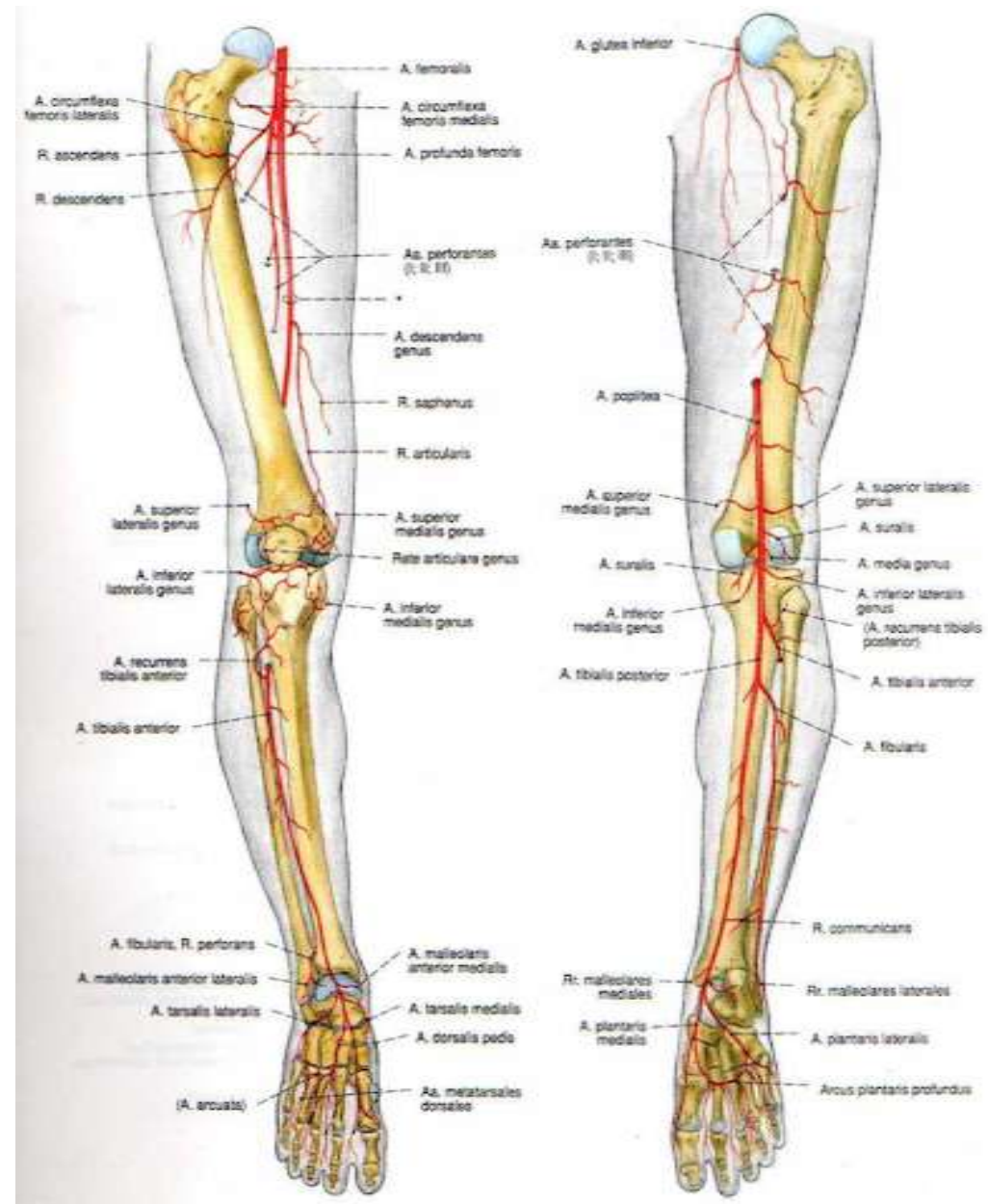

Figure 2. Femoral artery and its branches (Paulsen and Washke, 2013)

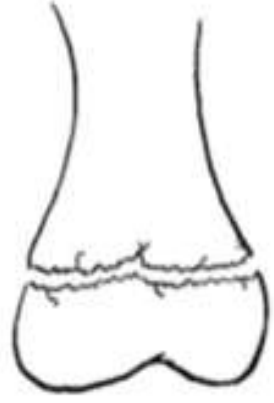

।

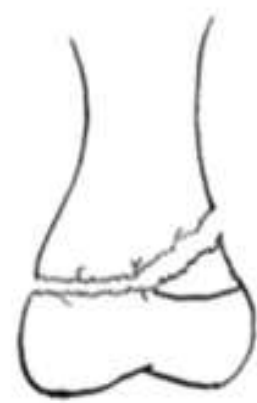

II

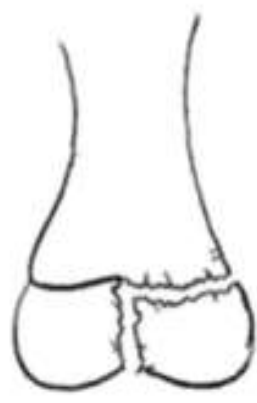

III

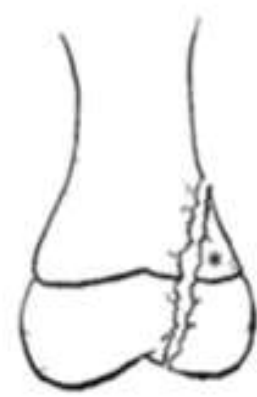

IV

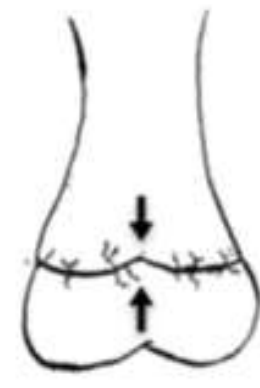

V

Figure 3. Salter-Harris fracture classification (Cepela et al., 2016)

Type I fracture is a fracture occurs in the physis that separates the metaphysis and epiphysis. Type II SH fracture, the fracture line passes through the physis and get to the metaphysis. Broken fragments of metaphysis are called Thurston-Holland fragments. Type III SH fracture, the fracture line fractures pass through the physis and get to the epiphysis. Type IV SH fracture, the fracture line get through physis, metaphysis and epiphysis. Type V SH fracture is caused by large pressure resulting in injury to physis (compression) (Cepela et al., 2016; Murdock, 2015).

In our patient, we found a neurovascular disturbance based on pulse oxi- 
metry examination on digiti I-V, no pulse on artery dorsalis pedis and Capillary Refill Test result more than 2 seconds. On motoric examination, the patient cannot move the left foot fingers and dorsiflexion but on the sensory examination patient still can feel the tactile stimulation.

Our patients with left femoral artery occlusion et causa closed fracture distal femur (Salter-Harris type II) managed by surgery to release the femoral artery with internal fixation to the distal femur using Kirschner wire (minimally invasive) and massage to the femoral artery give optimal results.

After surgery, on the first day postoperative, $\mathrm{SpO} 2$ on the digiti I to $\mathrm{V}$ left pedis is displayed in Table 2. CT-angiography was performed for monitoring and evaluation purposes.

Table 2. The Result of SpO2 Examination Postoperative

\begin{tabular}{cccccc}
\hline Time & Dig I & Dig II & Dig III & Dig IV & Dig V \\
\hline o Min & $64 \%$ & $57 \%$ & $64 \%$ & $55 \%$ & $62 \%$ \\
1 Hrs & $86 \%$ & $89 \%$ & $85 \%$ & $88 \%$ & $85 \%$ \\
$24 \mathrm{Hrs}$ & $97 \%$ & $98 \%$ & $99 \%$ & $98 \%$ & $97 \%$ \\
$48 \mathrm{Hrs}$ & $99 \%$ & $98 \%$ & $100 \%$ & $98 \%$ & $97 \%$ \\
$72 \mathrm{Hrs}$ & $99 \%$ & $100 \%$ & $98 \%$ & $99 \%$ & $98 \%$ \\
\hline
\end{tabular}

\section{On CT-angiography examination} there is no narrowing, widening, obstruction or extravasation of contrast in the common femoral artery, superficial femoral artery, popliteal artery, and posterior artery and left anterior tibialis. On the second day postoperative, the patient has not been able to move the fingers and left ankle with $\mathrm{SpO} 2$ displayed in Table 2.

On the third day, the patient can practice to standing up, then on the fourth day he can practice walking but cannot dorsiflexion and is allowed to go home.

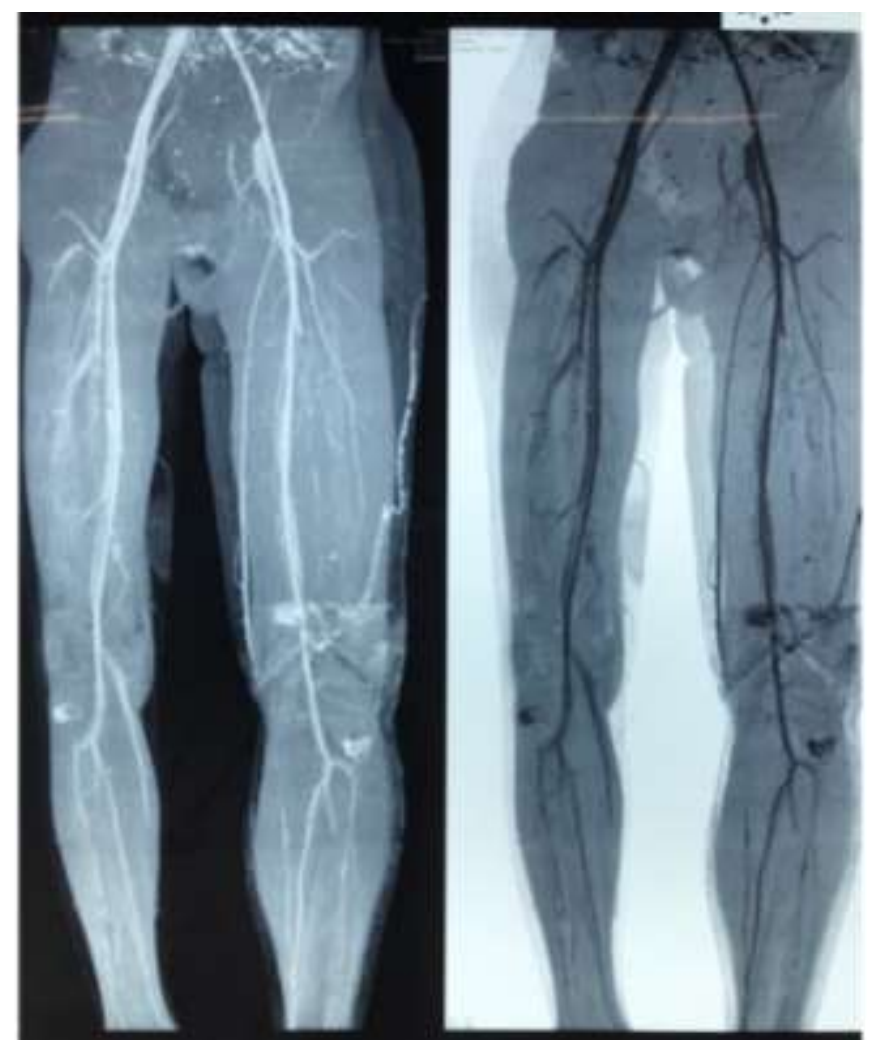

Figure 4. Postoperative Angiography of Lower Extremity 


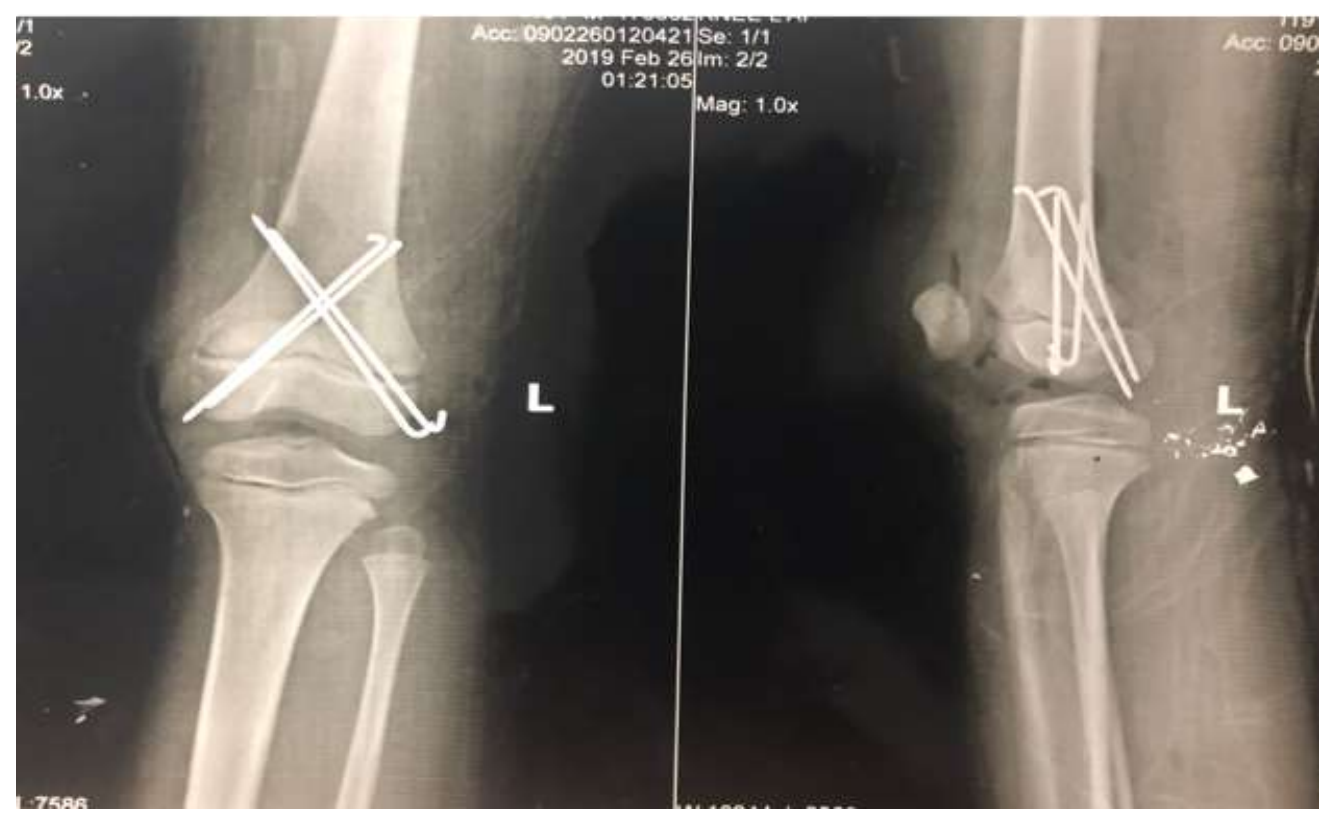

Figure 5. X-ray Postoperative, Internal Fixation with Kirschner Wire

\begin{abstract}
CONCLUSION
Volkmann's Ischemic Contracture caused by disruption of arterial flow to the muscles. Epiphysis fractures at the distal femur can cause occlusion in the arteries and become muscle ischemia.

Our patient with left femoral artery occlusion et causa closed fracture distal femur (Salter-Harris type II) managed by surgery to release the femoral artery with internal fixation to the distal femur using Kirschner wire (minimally invasive) and massage to the femoral artery give an optimal result.
\end{abstract}

Further research is needed to determine the prognosis of the Salter-Harris fracture on the distal femur with the arterial occlusion and its required management.

\footnotetext{
REFERENCE

Abela CB, Vanniasinkham SH (2003). Clinical Implications of ischaemia-reperfusion injury. ELSEVIER Pathophysiology. 9: 229-240.

Ajankar VP, Panshewdikar PN, Thakre G, Mane U, Tekale V (2014). Morpholo-
}

gical Study on Branching Pattern of Femoral Artery: A Cadaveric Study. Asian Journal of Biomedical and Pharmaceutical Sciences. 4(28): 3438.

Aydin A, Topal M, Tuncer K, Senocak E (2012). Salter-Harris type III and Type IV combined fracture of the distal femoral epiphysis: A case report. Case Report In Medicine.

Basbug HS, Gocer H, Ozisik K (2017). Huge leg hematoma due to vascular disruption following femur fracture: An Industrial Accident Catastrophe. AMAJ. 1: 12-14.

Cepela DJ, Tartaglione JP, Dooley TP, Patel $P N$ (2016). Classification in brief: Salter-Harris classification of pediatric physeal fracture. Clin Orthop Relat Res. 474: 2531-2537.

Farzad M, Hosseini SA, Fahimi NA, Layeghi F (2010). Non surgical of established Forearm's Volkmann contracture in child: A case report. Iranian Rehabilitation Journal. 8(11).

Kingori J, Gakuu LN (2010). Volkmann's ischaemic contracture following acute 
compartment syndrome: A Case Report. East Africa Orthopaedic Journal. 4: 56-58.

Kuleta-Bosak E, Bozek P, Kluczweska E, Tomazewski R, Machnik-Broncel J (2010). Salter-Harris Type II Fracture of The Femoral Bone in a 14 Years Old Boy: Case Report. Polish Journal of Radiology. 75(1): 92-97.

Maheshwar L, Kiran KK, Vamshi KC, Siva PR (2015). Volkmann's ischaemic contracture with atrophic non-union of ulna managed by bone shortening and transposition of radial autograft. Journal of Orthopaedic Case Reports. 5(1): 65-68.

Mayer S, Albright JC, Stoneback JW (2015). Pediatric knee dislocation and physeal fracture about the knee. J Am Acad Ortho Surg. 23: 571-580.

McKenna SM, Hamilton SW, Baker SL (2013). Salter Harris fracture of the distal femur: Learning point from 2 cases compared. Journal of Investigation Medicine High Impact Case Report.

Murdock M (2015). Unexpected salterharris type II fracture of the proximal phalanx of the second toe: a Chiropractic perspective. J Can Chiropr Assoc. 59(4): 410-416.

Paulsen F, Washke J (2013). Sobotta Atlas Human Anatomy. Vol. 2, 15th ed., London: Urban \& Fischer.
Reurings JC, Verhofstad MHJ (2007). The Volkmann ischemic contracture of the forearm is preventable. European Journal of Trauma and Emergency Surgery. 33: 539-544.

Smith DA, Bhimji SS (2018). Acute Arterial Occlusion. NCBI StatPearls.

Sperofoulos NK (2014). Classification of distal radius physeal fracture not included in the salter-harris system. The Open Orthopaedic Journal. 8: 219-224.

Wind TC, Saunders SM, Barfield WR, Mooney JF, Hartsock LA (2012). Compartment syndrome after low-energy tibia fractures sustained during athletic competition. J Orthop Trauma. 26: 33-36.

Zagorac S, Lesic A, Bumbasiravic M (2016). A case of acute billateral femur fracture with vascular injury. Journal of Acute Disease. 5(1): 86-89.

Zlotorowicz M, Czubak J (2014). Vascular Anatomy and Blood Supply to the Femoral Head. Springer.

Zoran B, Marija J, Daniela G, Roza DT, Jasmina N (2016). Volkmann's contracture as a complication of supracondylar fracture of humerus in children: Case Report. SANAMED. 11(1): 57-61. 